\title{
Three-month Prostate-specific Antigen Level After Androgen Deprivation Therapy Predicts Survival in Patients With Metastatic Castration-sensitive Prostate Cancer
}

\author{
NAOHIRO FUJIMOTO ${ }^{1}$, MASAKI SHIOTA ${ }^{2}$, TAKUO MATSUKAWA ${ }^{1}$,

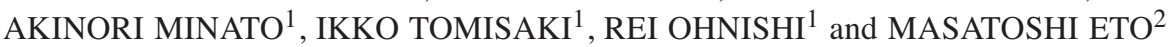 \\ ${ }^{1}$ Department of Urology School of Medicine, \\ University of Occupational and Environmental Health, Kitakyushu, Japan; \\ ${ }^{2}$ Department of Urology, Graduate School of Medical Sciences, Kyushu University, Fukuoka, Japan
}

\begin{abstract}
Background/Aim: Although upfront combination therapies with androgen deprivation are recommended for patients with castration-sensitive prostate cancer (CSPC), combination therapies may be excessive for some patients. The aim of this study was to identify patients with favorable outcome under androgen deprivation therapy (ADT) alone. Patients and Methods: This study consisted of 242 patients with CSPC who received ADT alone. The association between 3-month prostate-specific antigen (PSA) value after ADT and survival was analyzed. Results: The median overall survival for men with high-volume and/or high-risk cancer and those with low-volume low-risk cancer were 48.0 months and 103.0 months, respectively $(p \leq 0.0001)$. Notably, in patients with low-volume low-risk cancer, the median overall survival for patients who achieved $P S A \leq 2 \mathrm{ng} / \mathrm{ml}$ at 3 months after ADT initiation was quite long at 112.0 months. Conclusion: Conventional ADT may be sufficient and upfront combination therapy may be excessive for those patients with favorable outcome.
\end{abstract}

Androgen deprivation therapy (ADT) has been a standard treatment for patients with metastatic prostate cancer for more than seven decades. However, recent developments in novel therapies have provided a dramatic change in treatment strategy for those with metastatic castration-sensitive prostate

This article is freely accessible online.

Correspondence to: Naohiro Fujimoto MD, Ph.D., Department of Urology, University of Occupational and Environmental Health, 11 Iseigaoka, Yahatanishi, Kitakyushu 807-8556, Japan. Tel.: +81 936917446, Fax: +81 936038724, e -mail: n-fuji@med.uoeh-u.ac.jp

Key Words: Prostate cancer, castration sensitive, androgen deprivation therapy, survival, prostate-specific antigen. cancer (mCSPC). Large-scale phase III clinical trials, Chemohormonal Therapy versus Androgen Ablation Randomized Trial for Extensive Disease in Prostate Cancer (CHAATED) (1) and A study of abiraterone acetate plus lowdose prednisone plus ADT versus ADT alone in newly diagnosed participants with high-risk, metastatic hormonenaïve prostate cancer (LATITUDE) (2), have demonstrated a significant survival benefit associated with upfront docetaxel and abiraterone acetate (Abi) use for patients with highvolume and high-risk mCSPC, respectively. In recent post hoc subgroup analyses of the clinical trial, Systemic Therapy in Advancing or Metastatic Prostate Cancer: evaluation of drug efficacy (STAMPEDE) (3), it was concluded that for patients with any tumor volume and risk, upfront docetaxel and Abi were beneficial irrespective of cancer volume or risk $(4,5)$. More recent trials also indicated survival benefits in patients with low-volume or low-risk mCSPC receiving upfront use of later generation androgen pathway inhibitors such as enzalutamide (6) and apalutamide (7). A review and network meta-analysis also demonstrated that ADT plus enzalutamide improved survival compared to that with ADT alone for low-volume disease (8). The European Association of Urology (9) and American Urological Association/ American Society for radiation Oncology/Society of Urologic Oncology (10) guidelines recommend combination docetaxel, Abi plus prednisone, apalutamide, or enzalutamide with ADT as first-line therapy for all patients with mCSPC which reflects current standard of care practices. These agents, however, can cause agent-specific adverse events. Docetaxel has been associated with leukocytopenia, alopecia, and neuropathy; Abi can cause hypertension and hypokalemia; enzalutamide and apalutamide can cause fatigue and rash, respectively $(1,2,6,7)$.

Some patients with mCSPC achieve long-term survival under ADT alone. In the CHAATED trial, for example, more than $50 \%$ of patients with low-volume disease survived 
longer than 5 years under ADT alone (1). Upfront docetaxel and Abi may be excessive treatment for patients with longterm survival taking ADT alone; the adverse events caused by multiple agents may exceed the benefit. Therefore, being able to predict oncological outcomes to avoid unnecessary treatment-related toxicity and medical expense is necessary.

Biomarkers to effectively predict primary ADT responses and to identify patients who may obtain long-term survival under ADT alone are required. Biomarkers that can be determined early in the treatment process would help avoid treatment delays for men who require combination therapy with ADT. As demonstrated in the CHAATED (1) and LATITUDE (2) trials, a 3-month delay in starting a combination therapy may be acceptable. In our daily clinical work, we have observed patients who experience early prostate-specific antigen (PSA) decline and who have achieved long-term survival under primary ADT only. Therefore, in the present study, we investigated the association between survival and PSA value early in the treatment process in patients receiving treatment with ADT.

\section{Patients and Methods}

Patients and treatment. Consecutive patients with MCSPC who received ADT at the University of Occupational and Environmental Health Hospital and Kyushu University Hospital between April 2004 and December 2019 were considered for analysis. Patients who started primary ADT at other hospitals who were then transferred to our hospitals were also included. All patients received primary ADT with castration (either surgical, luteinizing hormonereleasing hormone agonist or antagonist) with or without firstgeneration anti-androgens (bicalutamide or hydroxyflutamide). PSA was measured every month after ADT initiation for several months. In patients with low and stable PSA levels, PSA was measured every 3 months. Imaging studies were performed at each physician's discretion. Patients who received radiation therapy, chemotherapy, or later generation androgen pathway inhibitors such as Abi within 6 months after ADT initiation were excluded.

Definition of disease volume, risk and castration-resistant disease. Disease volume and risk were defined according to the CHAATED (1) and LATITUDE (2) trials, respectively. In brief, high volume was defined as the presence of visceral metastases with/without $\geq 4$ bone metastases and at least one metastatic lesion outside the vertebral column and pelvis. High-risk patients were defined as those with at least two of the following three factors; Gleason score $\geq 8, \geq 3$ bone metastases, visceral metastases. Castration-resistant prostate cancer (CRPC) was defined according to the European Association of Urology guideline (9) as follows: castration levels of serum testosterone $\leq 50 \mathrm{ng} / \mathrm{dl}$ plus either biological progression (three consecutive rises in PSA 1 week apart resulting in two 50\% increases over the nadir, and a PSA $>2 \mathrm{ng} / \mathrm{ml}$ ) or radiological progression.

Statistical analysis. Differences in continuous and categorical variables were tested using a Mann-Whitney U-test and chi-squared test, respectively. Overall survival (OS), prostate cancer-specific survival (PCSS), and CRPC-free survival were defined as the time from ADT initiation to death from any cause, prostate cancer death, and progression to CRPC, respectively. Survival rates were calculated with the Kaplan-Meier method and a log-rank test was used for comparison of survival between groups. Univariate analysis was performed using EZR (Easy R, Vienna, Austria), which is a graphical user interface for $\mathrm{R}$ (The $\mathrm{R}$ Foundation for Statistical Computing). A value of $p \leq 0.05$ was considered statistically significant.

Ethics approval. The Institutional Review Boards of University of Occupational and Environmental Health (UOEHCRB19-050) and Kyushu University (29-438) approved this study.

\section{Results}

Patient characteristics. A total of 317 patients with mCSPC were identified during the study period. Of them, 19 were excluded because they received radiation therapy within 6 months after primary ADT initiation; 56 patients were excluded owing to a lack of detailed clinical and follow-up data. The remaining 242 patients were eligible for analysis and baseline characteristics are shown in Table I. Median age and initial PSA were 73 [interquartile range $(\mathrm{IQR})=67-78$ ] years and 203.2 (IQR=68.9-646.0) $\mathrm{ng} / \mathrm{ml}$, respectively. Patients with high-volume and high-risk cancer comprised $156(64.5 \%)$ and 167 (69.0\%), respectively. Patients with high-volume and/or high-risk cancer and those with lowvolume low-risk cancer comprised 178 (74.0\%) and 64 $(26.0 \%)$, respectively.

Survival and PSA. The median follow-up time from ADT initiation, was 44 (IQR=23-72) months. The median OS for men with low-volume low-risk cancer was 103.0 months compared with 48.0 months for men with high-volume and/or high-risk cancer and was significantly longer [hazard ratio $(\mathrm{HR})=0.4495 \%$, confidence interval $(\mathrm{CI})=0.31-0.63$, $p \leq 0.0001$, Figure 1]. Heterogeneity in survival was investigated in volume and risk categories The PSA response was used to distinguish patients with favorable outcomes from those with unfavorable outcomes. We compared OS according to PSA cut-off levels of $0.5,1,2$ and $4 \mathrm{ng} / \mathrm{ml}$ at 3 months following ADT initiation. In patients with highvolume and/or high-risk cancer, none of the PSA cut-off values distinguished patients with favorable from those the unfavorable survival (Figure 2A). In patients with lowvolume low-risk cancer, PSA cut-offs of $0.5,1$ and $4 \mathrm{ng} / \mathrm{ml}$ at 3 months were not able to distinguish between survival groups; however, a PSA cut-off of $2 \mathrm{ng} / \mathrm{ml}$ distinguish patients who achieved long-term OS from those who achieved only short-term OS (Figure 2B). The median OS was 112.0 months for patients with 3 -month PSA $\leq 2 \mathrm{ng} / \mathrm{ml}$ and 60.0 months for those with 3-month PSA $>2 \mathrm{ng} / \mathrm{ml}$, respectively $(\mathrm{HR}=0.39,95 \% \mathrm{CI}=0.16-0.93, p=0.034)$. Fiveyear OS rates for patients with 3-month PSA $\leq 2 \mathrm{ng} / \mathrm{ml}$ and 
Table I. Baseline patient characteristics $(N=242)$.

\begin{tabular}{|c|c|c|}
\hline Characteristic & Subgroup & Value \\
\hline Age at ADT start, years & Median (IQR) & $73(67-78)$ \\
\hline \multirow[t]{5}{*}{ Performance status, n (\%) } & 0 & $92(38.0)$ \\
\hline & 1 & $67(27.7)$ \\
\hline & 2 & $12(5.0)$ \\
\hline & 3 & $5(2.1)$ \\
\hline & Unknown & $66(27.3)$ \\
\hline PSA prior to ADT, $\mathrm{ng} / \mathrm{ml}$ & Median (IQR) & $203.2(68.9-646.0)$ \\
\hline \multirow[t]{6}{*}{ Gleason group, n (\%) } & 1 & $4(1.7)$ \\
\hline & 2 & $9(3.7)$ \\
\hline & 3 & $21(8.7)$ \\
\hline & 4 & $74(30.6)$ \\
\hline & 5 & $130(53.7)$ \\
\hline & Unknown & $4(1.7)$ \\
\hline \multirow[t]{4}{*}{ Primary tumor stage, n (\%) } & $\leq \mathrm{T} 2$ & $42(17.4)$ \\
\hline & T3 & $127(52.5)$ \\
\hline & $\mathrm{T} 4$ & $70(28.9)$ \\
\hline & Tx & $3(1.2)$ \\
\hline \multirow[t]{3}{*}{ Regional node status, n (\%) } & NO & $86(35.5)$ \\
\hline & $\mathrm{N}+$ & $131(54.1)$ \\
\hline & $\mathrm{Nx}$ & $25(10.3)$ \\
\hline \multirow[t]{3}{*}{ Number of bone metastasis, n (\%) } & $\leq 4$ & $86(35.5)$ \\
\hline & $>4$ & $131(54.1)$ \\
\hline & Unknown & $25(10.3)$ \\
\hline \multirow[t]{3}{*}{ Visceral metastasis, n (\%) } & No & $208(86.0)$ \\
\hline & Yes & $31(12.8)$ \\
\hline & Unknown & $3(1.2)$ \\
\hline \multirow[t]{3}{*}{ Disease volume, $\mathrm{n}(\%)$} & High & $156(64.5)$ \\
\hline & Low & $85(35.1)$ \\
\hline & Unknown & $1(0.4)$ \\
\hline \multirow[t]{2}{*}{ Disease risk, n (\%) } & High & $167(69.0)$ \\
\hline & Low & $75(31.0)$ \\
\hline
\end{tabular}

ADT: Androgen deprivation therapy; IQR: interquartile range.

$>2 \mathrm{ng} / \mathrm{ml}$ were $85.3 \%$ and $48.3 \%$, respectively. Patients with 3-month PSA $\leq 2 \mathrm{ng} / \mathrm{ml}$ had substantially longer OS; however, the OS for those with 3-month PSA $>2 \mathrm{ng} / \mathrm{ml}$ was not significantly different from those patients with highvolume and/or high-risk disease. PCSS and CRPC-free survival also followed similar patterns (Figure 3A and B). Patients with low-volume low-risk cancer and with 3-month PSA $\leq 2 \mathrm{ng} / \mathrm{ml}$ had significantly longer PCSS than those with a 3-month PSA $>2 \mathrm{ng} / \mathrm{ml}$ (median: not reached vs. 90.5 months; $\mathrm{HR}=0.36,95 \% \mathrm{CI}=0.13-0.94, p=0.037)$. In patients with low-volume low-risk cancer, the median CRPC-free survival of those with a low PSA level was 57.3 months while it 24 months for the high PSA group (HR=0.38, 95\% $\mathrm{CI}=0.17-0.85, p=0.002)$. PSA values at 1 or 2 months after ADT initiation did not predict survival (data not shown).

The results from univariate analysis of data for patients with low-volume low-risk cancer revealed that initial PSA [higher vs. lower than $60 \mathrm{ng} / \mathrm{ml}$ (median)], Gleason group (13 vs. 4, 5), T-stage (1, 2 vs. 3, 4) and nodal status (0 vs. 1)

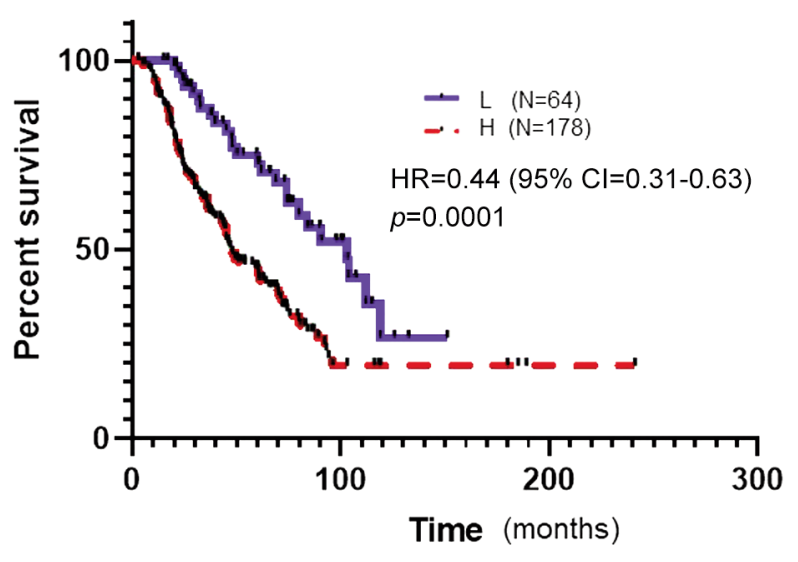

Figure 1. Kaplan-Meier estimate of overall survival for patients with low-volume and low-risk (L) prostate cancer versus those with Highvolume and/or high-risk $(H)$ disease.

were not associated with long-term survival but 3-month PSA $\leq 2 \mathrm{ng} / \mathrm{ml}$ was significantly associated with long-term survival (Table II). Multivariate analysis was not performed because the number of patients $(n=64)$ and death $(n=25)$ of patients with low-volume low-risk cancer disease were too small for the analysis.

\section{Discussion}

In contrast to prostate cancer therapy options of the past, we currently have many first-line treatment options for mCSPC, including a combination of ADT plus docetaxel (1), novel androgen pathway inhibitors $(2,3,6,7)$ and local radiation (11). A post hoc subgroup analyses of recent clinical trials on treatment options for mCSPC indicated a survival benefit across all outcome measures in those patients who were administered combination therapy regardless of tumor volume and risk. For patients with low-risk cancer included in the LATITUDE and CHAATED trials, Abi plus ADT demonstrated an OS benefit (low-risk: $\mathrm{HR}=0.66,95 \%$ $\mathrm{CI}=0.44-0.98$; low-volume: $\mathrm{HR}=0.64$, 95\% CI=0.32-9.97) (4). For patients with low-volume cancer in the CHAATED trial, the median OS for those on docetaxel plus ADT was 93.2 months and was 76.7 months for those on ADT alone. The HR was consistent between those with low- and highvolume cancer $(\mathrm{HR}=0.76,95 \% \mathrm{CI}=0.54-1.07$; and $\mathrm{HR}=0.81$, $95 \% \mathrm{CI}=0.64-1.02$, respectively) (5). These analyses suggest that combination treatment can provide oncologic benefit for patients with mCSPC irrespective of cancer risk or volume.

In contrast, the aggregate data analysis of the CHAATED and Groupe d'Étude des Tumeurs Uro-Genital and Association Française d'Urologie (GTUG-AFU15) trials indicated a survival benefit for those on upfront docetaxel versus $\mathrm{ADT}$ alone in patients with high-volume cancer; 

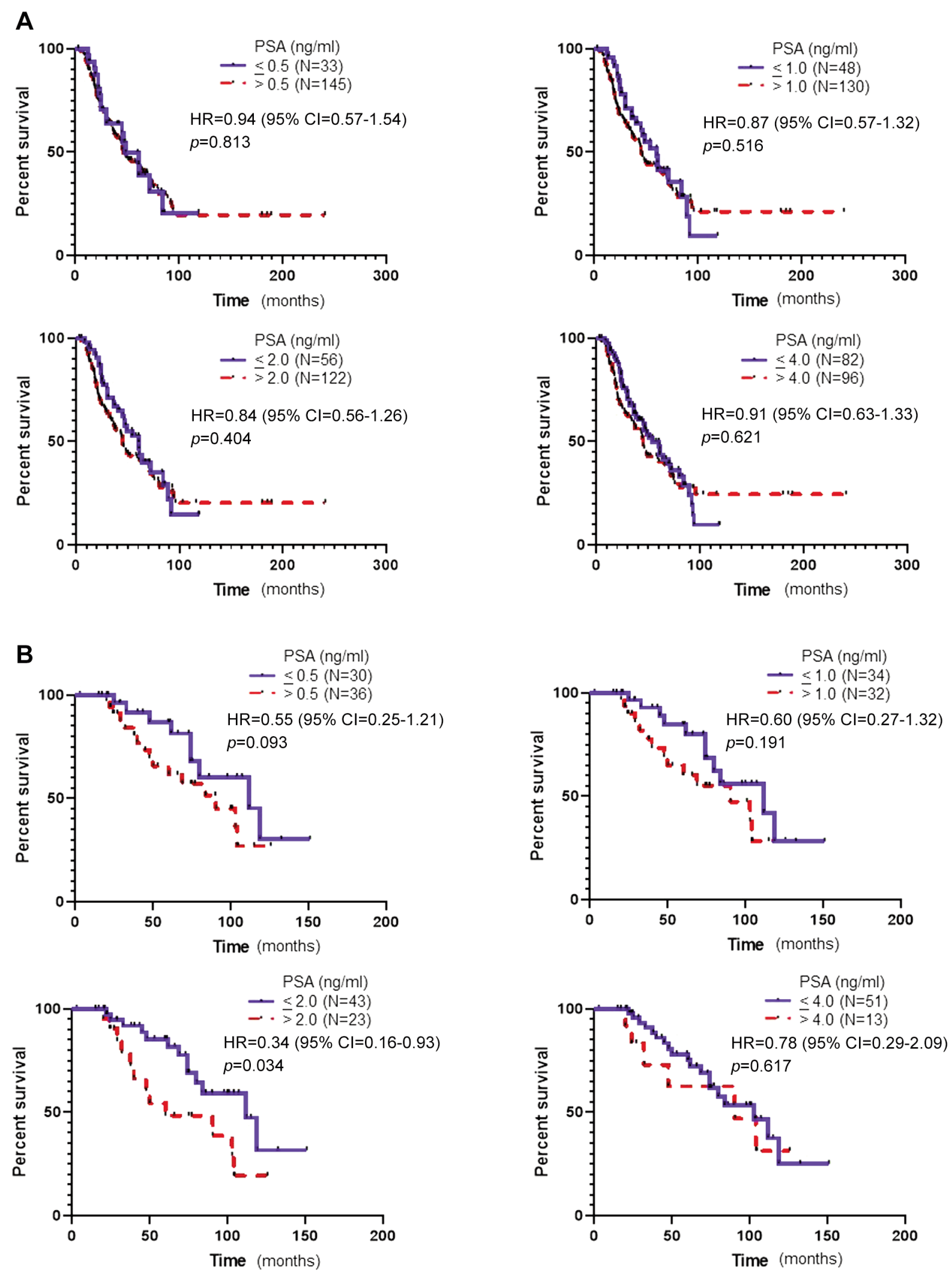

Figure 2. Kaplan-Meier estimate of overall survival according to different 3-month prostate-specific antigen (PSA) cut-off values of 0.5, 1, 2 and 4 $\mathrm{ng} / \mathrm{ml}$ in patients with high-volume and/or high-risk prostate cancer $(A)$ and those with low-volume low-risk prostate cancer $(B)$. 

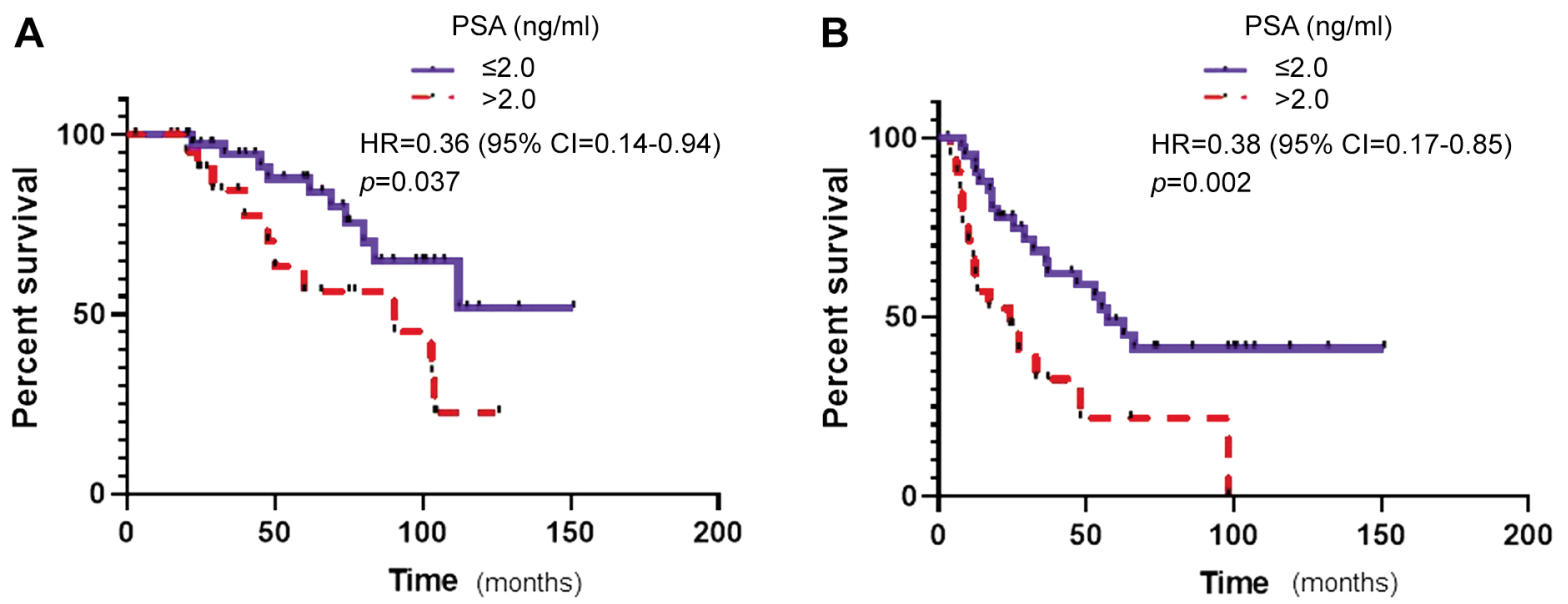

Figure 3. Kaplan-Meier estimate of prostate cancer-specific (A) and castration-resistant prostate cancer-free (B) survival for patients with lowvolume low-risk cancer.

Table II. Univariate analysis for risk of death.

\begin{tabular}{lllll}
\hline Variable & Subgroup & HR & 95\% CI & $p$-Value \\
\hline Initial PSA & $\leq 60$ vs. $>60 \mathrm{ng} / \mathrm{ml}$ & 1.281 & $0.5336-3.073$ & 0.580 \\
Gleason group & $1-3$ ss. 4,5 & 1.132 & $0.4797-2.672$ & 0.777 \\
Primary tumor stage & 1,2 s. 3,4 & 0.8145 & $0.3002-2.21$ & 0.687 \\
Nodal stage & 0 vs. 1 & 1.022 & $0.4439-2.352$ & 0.959 \\
3-Month PSA & $\leq 2.0$ vs. $>2.0 \mathrm{ng} / \mathrm{ml}$ & 2.292 & $1.042-5.043$ & 0.039 \\
\hline
\end{tabular}

PSA: Prostate-specific antigen; HR: hazard ratio; CI: confidence interval.

however, this benefit was not seen for those with low-volume cancer (pooled $\mathrm{HR}=1.03,95 \% \mathrm{CI}=0.77-1.38$ ) (13). According to the LATITUDE trial, the long-term follow-up did not indicate a survival benefit with administration of upfront Abi in patients with low-volume disease $(\mathrm{HR}=0.72,95 \% \mathrm{CI}=0.47$ 1.10) (14). Therefore, benefits from addition of docetaxel or Abi in low-volume disease are still controversial.

Three-year OS rates for patients with low-risk and lowvolume cancer treated with ADT alone in the STAMPEDE trial were $78 \%$ and $77 \%$, respectively (4). For patients with low-volume cancer treated with ADT alone in the same trial, median OS and 5-year survival rate were 76.7 months and $57 \%$, respectively (5). In the GETUG-AFU15 trial, median OS for those with low-volume cancer was 83.4 months (13). In these cohorts, approximately $50 \%$ and $40 \%$ of patients with low-risk/volume disease treated with ADT alone survived longer than 5 and 7 years, respectively. Therefore, a subset of patients with mCSPC achieved long-term survival under ADT alone, suggesting that certain patients may not require combination therapy with ADT.

Combination therapies increase the risk of adverse events. Clinical trials suggest that docetaxel-induced febrile neutropenia may be more serious in patients with CSPC compared to those with CRPC $(1,12,15)$. Of the patients in the docetaxel arm of the CHAATED and STAMPEDE trials, $14 \%$ and 23\%, respectively, did not complete the planned six courses of docetaxel due to adverse events $(1,15)$. In the GETUG-AFU15 trial, $21 \%$ of patients in the docetaxel arm discontinued the drug due to adverse events (12). In addition, 16/1774 patients in three clinical trials died of docetaxel toxicity (16). When Abi was given in combination with ADT, $63 \%$ and $47 \%$ patients in the LATITUDE (2) and STAMPEDE (17) trials, respectively, experienced grade 3 or greater adverse events. Long-term use of prednisone with Abi may cause various steroid-related events and increased medical costs are also problematic. Appropriate early treatment decisions are therefore required to avoid unnecessary overtreatment, toxicities, and medical expenses.

PSA kinetics can predict oncological outcomes after primary ADT for mCSPC. One systematic review and metaanalysis indicated that a higher nadir PSA and shorter time to nadir were associated with shorter progression-free and OS (18). The time from ADT initiation to nadir PSA (19-21) along with the PSA level at 7 months from ADT initiation 
(21) were reported to be prognostic factors for men with mCSPC who received ADT alone. Although these biomarkers may predict survival, the optimal value of nadir and time to nadir PSA were not identified. It takes approximately 6 to 12 months to calculate the nadir and time to nadir PSA values (20-22) and these biomarkers are determined only retrospectively. In addition, using these biomarkers can delay initiation of additional docetaxel or androgen pathway inhibitors when patients have unfavorable cancer outcomes and need these agents as upfront combination therapy.

We demonstrated that 3-month PSA after ADT initiation can predict long survival in men with low-risk and lowvolume disease and that patients with 3-month PSA $\leq 2 \mathrm{ng} / \mathrm{ml}$ may not need combination therapy as first-line treatment. Combination therapy is recommended when 3-month PSA does not reach $\leq 2 \mathrm{ng} / \mathrm{ml}$, even if patients have low-risk and low-volume cancer, because of their poor prognosis under ADT alone. In patients with high-risk and/or high-volume disease, oncological outcomes were unfavorable irrespective of the 3-month PSA level, and in these cases, early combination therapy is indicated.

Polymorphisms in several genes that are associated with androgen signaling are associated with OS and CRPC-free survival (23). A recent study demonstrated that OS and CRPC-free survival varied by genotype of HSD3B1, which encodes $3 \beta$-hydroxysteroid dehydrogenase-1, in low-volume mCSPC (24). Molecular subtyping by gene-expression profiling may also predict treatment outcome in patients with mCSPC $(25,26)$. Hamid et al. suggested that those with the luminal B subtype of mCSPC benefited from addition of docetaxel to ADT, however, those with the basal subtype did not (26). These molecular biomarkers may be promising and will help identify the appropriate treatment for each patient with $\mathrm{mCSPC}$ in the future. At present, we propose that patients with low-risk and low-volume disease start ADT with simultaneous PSA monitoring. When 3-month PSA is $>2 \mathrm{ng} / \mathrm{ml}$, adding docetaxel or androgen pathway inhibitors to ADT should be considered. Patients with low-volume lowrisk cancer who achieve a level of PSA $\leq 2 \mathrm{ng} / \mathrm{ml}$ at 3 months are more likely to have a longer survival. Our patients' median OS was 112 months and ADT may be enough for such patients, especially for men with life expectancy shorter than 10 years, and adverse events of combination therapy may exceed the oncological benefit in these patients.

This study has several limitations. Our patients were Japanese only, and it has been shown that they have favorable responses to ADT (27-29). Further studies that include patients of other races are required for generalization of our results. Assessments of some of the prognostic biomarkers such as serum testosterone, alkaline phosphatase, hemoglobin, lactate dehydrogenase, albumin were not included in analyses because of the retrospective nature of this study and incomplete data in our database. Inter-observer variation of Gleason grade may exist because pathological diagnosis was made over a long period. We, however, do not think these factors have a great impact on our conclusions.

\section{Conclusion}

PSA level at 3 months after ADT initiation was associated with survival in patients with low-risk and low-volume $\mathrm{mCSPC}$ and those who achieved PSA $\leq 2 \mathrm{ng} / \mathrm{ml}$ at 3 months had a favorable outcome. ADT may be sufficient, and upfront docetaxel or androgen pathway inhibitors may be considered excessive treatment for these patients, especially for those with short life expectancy. In contrast, upfront combination therapy is recommended for patients with 3month PSA $>2.0 \mathrm{ng} / \mathrm{ml}$, even if they have low-volume and low-risk disease.

\section{Conflicts of Interest}

The Authors declare no potential conflicts of interest.

\section{Authors' Contributions}

All Authors contributed to the design of the study, acquisition and interpretation of the data. All Authors discussed, verified and approved the final version of the article.

\section{References}

1 Sweeney CJ, Chen YH, Carducci M, Liu G, Jarrard DF, Eisenberger M, Wong YN, Hahn N, Kohli M, Cooney MM, Dreicer R, Vogelzang NJ, Picus J, Shevrin D, Hussain M, Garcia JA and DiPaola RS: Chemohormonal therapy in metastatic hormone-sensitive prostate cancer. N Engl J Med 373: 737-746, 2015. PMID: 26244877. DOI: 10.1056/NEJMoa1503747

2 Fizazi K, Tran N, Fein L, Matsubara N, Rodriguez-Antolin A, Alekseev BY, Özgüroğlu M, Ye D, Feyerabend S, Protheroe A, De Porre P, Kheoh T, Park YC, Todd MB and Chi KN: Abiraterone plus prednisone in metastatic, castration-sensitive prostate cancer. N Engl J Med 377: 352-360, 2017. PMID: 28578607. DOI: 10.1056/NEJMoa1704174

3 Parmar MK, Sydes MR, Cafferty FH, Choodari-Oskooei B, Langley RE, Brown L, Phillips PP, Spears MR, Rowley S, Kaplan R, James ND, Maughan T, Paton N and Royston PJ: Testing many treatments within a single protocol over 10 years at MRC clinical trials unit at UCL: Multi-arm, multi-stage platform, umbrella and basket protocols. Clin Trials 14: 451-461, 2017. PMID: 28830236. DOI: 10.1177/1740774517725697

4 Hoyle AP, Ali A, James ND, Cook A, Parker CC, de Bono JS, Attard G, Chowdhury S, Cross WR, Dearnaley DP, Brawley CD, Gilson C, Ingleby F, Gillessen S, Aebersold DM, Jones RJ, Matheson D, Millman R, Mason MD, Ritchie AWS, Russell M, Douis H, Parmar MKB, Sydes MR and Clarke NW: Abiraterone in "high-" and "low-risk" metastatic hormone-sensitive prostate cancer. Eur Urol 76: 719-728, 2019. PMID: 31447077. DOI: 10.1016/j.eururo.2019.08.006 
5 Clarke NW, Ali A, Ingleby FC, Hoyle A, Amos CL, Attard G, Brawley CD, Calvert J, Chowdhury S, Cook A, Cross W, Dearnaley DP, Douis H, Gilbert D, Gillessen S, Jones RJ, Langley RE, MacNair A, Malik Z, Mason MD, Matheson D, Millman R, Parker CC, Ritchie AWS, Rush H, Russell JM, Brown J, Beesley S, Birtle A, Capaldi L, Gale J, Gibbs S, Lydon A, Nikapota A, Omlin A, O'Sullivan JM, Parikh O, Protheroe A, Rudman S, Srihari NN, Simms M, Tanguay JS, Tolan S, Wagstaff J, Wallace J, Wylie J, Zarkar A, Sydes MR, Parmar MKB and James ND: Addition of docetaxel to hormonal therapy in low- and high-burden metastatic hormone-sensitive prostate cancer: Long-term survival results from the STAMPEDE trial. Ann Oncol 30: 1992-2003, 2019. PMID: 31560068. DOI: 10.1093/annonc/mdz396

6 Armstrong AJ, Szmulewitz RZ, Petrylak DP, Holzbeierlein J, Villers A, Azad A, Alcaraz A, Alekseev B, Iguchi T, Shore ND, Rosbrook B, Sugg J, Baron B, Chen and Stenzl A: ARCHES: A randomized, phase III study of androgen deprivation therapy with enzalutamide or placebo in men with metastatic hormonesensitive prostate cancer. J Clin Oncol 37: 2974-2986, 2019. PMID: 1329516. DOI: 10.1200/JCO.19.00799

7 Chi KN, Agarwal N, Bjartell A, Chung BH, Pereira de Santana Gomes AJ, Given R, Juárez Soto Á, Merseburger AS, Özgüroğlu M, Uemura H, Ye D, Deprince K, Naini V, Li J, Cheng S, Yu MK, Zhang K, Larsen JS, McCarthy S and Chowdhury S: Apalutamide for metastatic, castration-sensitive prostate cancer. N Engl J Med 381: 13-24, 2019. PMID: 31150574. DOI: 10.1056/NEJMoa1903307

8 Sathianathen NJ, Koschel S, Thangasamy IA, Teh J, Alghazo O, Butcher G, Howard H, Kapoor J, Lawrentschuk N, Siva S, Azad A, Tran B, Bolton D and Murphy DG: Indirect comparisons of efficacy between combination approaches in metastatic hormone-sensitive prostate cancer: A systematic review and network meta-analysis. Eur Urol 77: 365-372, 2020. PMID: 31679970. DOI: 10.1016/j.eururo.2019.09.004

9 Cornford P, van den Bergh RCN, Briers E, Van den Broeck T, Cumberbatch MG, De Santis M, Fanti S, Fossati N, Gandaglia G, Gillessen S, Grivas N, Grummet J, Henry AM, der Kwast THV, Lam TB, Lardas M, Liew M, Mason MD, Moris L, OpreaLager DE, der Poel HGV, Rouvière O, Schoots IG, Tilki D, Wiegel T, Willemse PM and Mottet N: EAU-EANM-ESTROESUR-SIOG Guidelines on Prostate Cancer. Part II-2020 Update: Treatment of relapsing and metastatic prostate cancer. Eur Urol Oct 7, 2020. PMID: 33039206. DOI: 10.1016/j.eururo. 2020.09.046

10 Lowrance WT, Breau RH, Chou R, Chapin BF, Crispino T, Dreicer R, Jarrard DF, Kibel AS, Morgan TM, Morgans AK, Oh WK, Resnick MJ, Zietman AL and Cookson MS: Advanced Prostate Cancer: AUA/ASTRO/SUO Guideline PART I. J Urol 205: 1-8, 2020. PMID: 32960679. DOI: 10.1097/JU.000000 0000001375

11 Parker CC, James ND, Brawley CD, Clarke NW, Hoyle AP, Ali A, Ritchie AWS, Attard G, Chowdhury S, Cross W, Dearnaley DP, Gillessen S, Gilson C, Jones RJ, Langley RE, Malik ZI, Mason MD, Matheson D, Millman R, Russell JM, Thalmann GN, Amos CL, Alonzi R, Bahl A, Birtle A, Din O, Douis H, Eswar C, Gale J, Gannon MR, Jonnada S, Khaksar S, Lester JF, O'Sullivan JM, Parikh OA, Pedley ID, Pudney DM, Sheehan DJ, Srihari NN, Tran ATH, Parmar MKB and Sydes MR: Radiotherapy to the primary tumour for newly diagnosed, metastatic prostate cancer (STAMPEDE): A randomised controlled phase 3 trial. Lancet 392: 2353-2366, 2018. PMID: 30355464. DOI: 10.1016/S0140-6736(18)32486-3

12 Gravis G, Fizazi K, Joly F, Oudard S, Priou F, Esterni B, Latorzeff I, Delva R, Krakowski I, Laguerre B, Rolland F, Théodore C, Deplanque G, Ferrero JM, Pouessel D, Mourey L, Beuzeboc P, Zanetta S, Habibian M, Berdah JF, Dauba J, Baciuchka M, Platini C, Linassier C, Labourey JL, Machiels JP, El Kouri C, Ravaud A, Suc E, Eymard JC, Hasbini A, Bousquet $\mathrm{G}$ and Soulie M: Androgen-deprivation therapy alone or with docetaxel in non-castrate metastatic prostate cancer (GETUGAFU 15): A randomised, open-label, phase 3 trial. Lancet Oncol 14: 149-158, 2013. PMID: 23306100. DOI: 10.1016/S14702045(12)70560-0

13 Gravis G, Boher JM, Chen YH, Liu G, Fizazi K, Carducci MA, Oudard S, Joly F, Jarrard DM, Soulie M, Eisenberger MJ, Habibian M, Dreicer R, Garcia JA, Hussain MHM, Kohli M, Vogelzang NJ, Picus J, DiPaola R and Sweeney C: Burden of metastatic castrate naive prostate cancer patients, to identify men more likely to benefit from early docetaxel: Further analyses of CHAARTED and GETUG-AFU15 studies. Eur Urol 73: 847855, 2018. PMID: 29475737. DOI: 10.1016/j.eururo.2018.02.001

14 Fizazi K, Tran N, Fein L, Matsubara N, Rodriguez-Antolin A, Alekseev BY, Özgüroğlu M, Ye D, Feyerabend S, Protheroe A, Sulur G, Luna Y, Li S, Mundle S and Chi KN: Abiraterone acetate plus prednisone in patients with newly diagnosed highrisk metastatic castration-sensitive prostate cancer (LATITUDE): Final overall survival analysis of a randomised, double-blind, phase 3 trial. Lancet Oncol 20: 686-700, 2019. PMID: 30987939. DOI: 10.1016/S1470-2045(19)30082-8

15 James ND, Sydes MR, Clarke NW, Mason MD, Dearnaley DP, Spears MR, Ritchie AW, Parker CC, Russell JM, Attard G, de Bono J, Cross W, Jones RJ, Thalmann G, Amos C, Matheson D, Millman R, Alzouebi M, Beesley S, Birtle AJ, Brock S, Cathomas R, Chakraborti P, Chowdhury S, Cook A, Elliott T, Gale J, Gibbs S, Graham JD, Hetherington J, Hughes R, Laing R, McKinna F, McLaren DB, O'Sullivan JM, Parikh O, Peedell C, Protheroe A, Robinson AJ, Srihari N, Srinivasan R, Staffurth J, Sundar S, Tolan S, Tsang D, Wagstaff J and Parmar MK: Addition of docetaxel, zoledronic acid, or both to first-line longterm hormone therapy in prostate cancer (STAMPEDE): Survival results from an adaptive, multiarm, multistage, platform randomised controlled trial. Lancet 387: 1163-1177, 2016. PMID: 26719232. DOI: 10.1016/S0140-6736(15)01037-5

16 Vale CL, Burdett S, Rydzewska LHM, Albiges L, Clarke NW, Fisher D, Fizazi K, Gravis G, James ND, Mason MD, Parmar MKB, Sweeney CJ, Sydes MR, Tombal B and Tierney JF: Addition of docetaxel or bisphosphonates to standard of care in men with localised or metastatic, hormone-sensitive prostate cancer: A systematic review and meta-analyses of aggregate data. Lancet Oncol 17: 243-256, 2016. PMID: 26718929. DOI: 10.1016/S1470-2045(15)00489-1

17 James ND, de Bono JS, Spears MR, Clarke NW, Mason MD, Dearnaley DP, Ritchie AWS, Amos CL, Gilson C, Jones RJ, Matheson D, Millman R, Attard G, Chowdhury S, Cross WR, Gillessen S, Parker CC, Russell JM, Berthold DR, Brawley C, Adab F, Aung S, Birtle AJ, Bowen J, Brock S, Chakraborti P, Ferguson C, Gale J, Gray E, Hingorani M, Hoskin PJ, Lester JF, Malik ZI, McKinna F, McPhail N, Money-Kyrle J, O'Sullivan J, Parikh O, Protheroe A, Robinson A, Srihari NN, Thomas C, 
Wagstaff J, Wylie J, Zarkar A, Parmar MKB and Sydes MR: Abiraterone for prostate cancer not previously treated with hormone therapy. N Engl J Med 377: 338-351, 2017. PMID: 28578639. DOI: 10.1056/NEJMoa1702900

18 Afriansyah A, Hamid ARAH, Mochtar CA and Umbas R: Prostate-specific antigen (PSA) kinetic as a prognostic factor in metastatic prostate cancer receiving androgen deprivation therapy: Systematic review and meta-analysis. F1000Res 7: 246, 2018. PMID: 29904592. DOI: 10.12688/f1000research.14026.1

19 Sasaki T, Onishi T and Hoshina A: Nadir PSA level and time to PSA nadir following primary androgen deprivation therapy are the early survival predictors for prostate cancer patients with bone metastasis. Prostate Cancer Prostatic Dis 14: 248-252, 2011. PMID: 21502970. DOI: 10.1038/pcan.2011.14

20 Tomioka A, Tanaka N, Yoshikawa M, Miyake M, Anai S, Chihara Y, Okajima E, Hirayama A, Hirao Y and Fujimoto K: Nadir PSA level and time to nadir PSA are prognostic factors in patients with metastatic prostate cancer. BMC Urol 14: 33, 2014. PMID: 24773608. DOI: 10.1186/1471-2490-14-33

21 Hamano I, Hatakeyama S, Narita S, Takahashi M, Sakurai T, Kawamura S, Hoshi S, Ishida M, Kawaguchi T, Ishidoya S, Shimoda J, Sato H, Mitsuzuka K, Tochigi T, Tsuchiya N, Arai Y, Habuchi T and Ohyama C: Impact of nadir PSA level and time to nadir during initial androgen deprivation therapy on prognosis in patients with metastatic castration-resistant prostate cancer. World J Urol 37: 2365-2373, 2019. PMID: 30729312. DOI: $10.1007 / \mathrm{s} 00345-019-02664-3$

22 Harshman LC, Chen YH, Liu G, Carducci MA, Jarrard D, Dreicer R, Hahn N, Garcia JA, Hussain M, Shevrin D, Eisenberger M, Kohli M, Plimack ER, Cooney M, Vogelzang NJ, Picus J, Dipaola R and Sweeney CJ: Seven-month prostatespecific antigen is prognostic in metastatic hormone-sensitive prostate cancer treated with androgen deprivation with or without docetaxel. J Clin Oncol 36: 376-382, 2018. PMID: 29261442. DOI: 10.1200/JCO.2017.75.3921

23 Fujimoto N, Shiota M, Tomisaki I and Minato A: Gene polymorphism-related individual and interracial differences in the outcomes of androgen deprivation therapy for prostate cancer. Clin Genitourin Cancer 15: 337-342, 2017. PMID: 28188049. DOI: $10.1016 /$ j.clgc.2017.01.006

24 Hearn JWD, Sweeney CJ, Almassi N, Reichard CA, Reddy CA, Li H, Hobbs B, Jarrard DF, Chen YH, Dreicer R, Garcia JA, Carducci MA, DiPaola RS, Sharifi N. HSD3B1 Genotype and clinical outcomes in metastatic castration-sensitive prostate cancer. JAMA Oncol 6: e196496, 2020. PMID: 32053149. DOI: 10.1001/jamaoncol.2019.6496
25 Zhao SG, Chang SL, Erho N, Yu M, Lehrer J, Alshalalfa M, Speers C, Cooperberg MR, Kim W, Ryan CJ, Den RB, Freedland SJ, Posadas E, Sandler H, Klein EA, Black P, Seiler R, Tomlins SA, Chinnaiyan AM, Jenkins RB, Davicioni E, Ross AE, Schaeffer EM, Nguyen PL, Carroll PR, Karnes RJ, Spratt DE and Feng FY: Associations of luminal and basal subtyping of prostate cancer with prognosis and response to androgen deprivation therapy. JAMA Oncol 3: 1663-1672, 2017. PMID: 28494073. DOI: 10.1001 /jamaoncol.2017.0751

26 Hamid A, Wang XV, Chen YH, Feng FY, Den RB and Attard G: Outcomes, responses to therapy vary based on basal-luminal subtype in metastatic prostate cancer. Genitourinary Cancers Symposium. Abstract \#162, February 13, 2020. Available at: https://meetinglibrary.asco.org/record/184248/abstract

27 Fukagai T, Namiki TS, Carlile RG, Yoshida H and Namiki M: Comparison of the clinical outcome after hormonal therapy for prostate cancer between Japanese and Caucasian men. BJU Int 97: 1190-1193, 2006. PMID: 16686710. DOI: 10.1111/j.1464410X.2006.06201.x

28 Fujimoto N, Kubo T, Inatomi H, Bui HT, Shiota M, Sho T and Matsumoto T: Polymorphisms of the androgen transporting gene SLCO2B1 may influence the castration resistance of prostate cancer and the racial differences in response to androgen deprivation. Prostate Cancer Prostatic Dis 16: 336-340, 2013. PMID: 23896622. DOI: 10.1038/pcan.2013.23

29 Fukasawa S, Suzuki H, Kawaguchi K, Noguchi H, Enjo K, Tran $\mathrm{N}$, Todd M, Fizazi K and Matsubara N: Efficacy and safety of abiraterone acetate plus prednisone in Japanese patients with newly diagnosed, metastatic hormone-naïve prostate cancer: A subgroup analysis of LATITUDE, a randomized, double-blind, placebo-controlled, phase 3 study. Jpn J Clin Oncol 48: 10121021, 2018. PMID: 30371895. DOI: 10.1093/jjco/hyy 129

Received November 14, 2020

Revised November 28, 2020

Accepted December 1, 2020 